
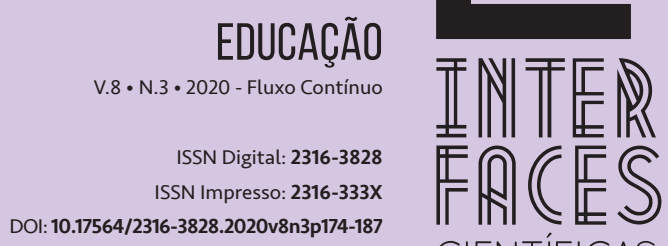

CIENTÍFICAS

\section{INTERAÇÕES DOCENTES EM BRINCADEIRAS E A AUTONOMIA DE CRIANCAS NO 10 ANO DO ENSINO FUNDAMENTAL}

TEACHING INTERACTIONS IN CHLLDREN AND THE AUTONOMY OF CHILDREN IN THE IST YEAR OF FUNDAMENTAL EDUCATION

INTERACCIONES DOCENTES EN BRINCADERAS Y LA AUTONOMÍA DE NNÑOS EN EL 10 AÑO DE LA ENSEÑANZA FUNDAMENTAL

Camila Tanure Duarte ${ }^{1}$ Fernando Donizete Alves ${ }^{2}$ Aline Sommerhalder ${ }^{3}$

\section{RESUMO}

Apresenta resultados de uma pesquisa concluída e aborda relações sociais entre professora e crianças em contextos de brincadeiras, realizadas no primeiro ano do Ensino Fundamental. Brincar é ato e aprendizagem social, porém pouco presente e valorizado no ensino fundamental. Objetivou descrever ações de interação docente realizadas com crianças em contextos de brincadeiras no ensino fundamental, analisando essas ações no processo de construção ou fortalecimento da autonomia das crianças. Fundamentada na abordagem qualitativa de pesquisa, foi realizada por meio de observação participante da rotina de uma turma de crianças e sua professora, em contextos de brincadeiras, com registros escritos em diários de campo. Foram sujeitos, vinte e cinco crianças do primeiro ano do Ensino Fundamental e sua professora, de uma escola municipal do interior do estado de São Paulo. Os dados foram analisados na perspectiva qualitativa, a partir da literatura escolhida. Revelou-se que, em algumas situações, as crianças poderiam ter sido mais incentivadas e questionadas, fomentando mais oportunidades para diálogo entre elas e a professora. No entanto, predominaram ações docentes de incentivo ao protagonismo infantil nas brincadeiras, em escolhas realizadas, com participação na rotina e nas atividades, favorecendo a construção ou fortalecimento da autonomia das crianças. As interações sociais nas brincadeiras, em contexto escolar, que ocorrem entre professora e crianças, sendo, entre elas essenciais para a aprendizagem e desenvolvimento humano, pois a escola é também um lugar para viver a vida e as infâncias.

\section{PALAVRAS-CHAVE}

Interações Sociais. Brincadeiras. Práticas Educativas. Crianças. Autonomia. 


\section{ABSTRACT}

It presents results of a completed research and approaches social relations between teacher and children in play contexts, carried out in the first year of Elementary School. To play is an act and social learning, but little present and valued in elementary school. The purpose of this study was to describe actions of teacher interaction carried out with children in contexts of play in elementary school, analyzing these actions in the process of building or strengthening the autonomy of children. Based on the qualitative research approach, it was carried out through participant observation of the routine of a group of children and their teacher, in play contexts, with records written in field diaries. Twenty five children from the first year of elementary school and their teacher, from a municipal school in the interior of the state of São Paulo, were subjected. The data were analyzed from a qualitative perspective, based on the literature chosen. It turned out that in some situations, children could have been more encouraged and questioned, fostering more opportunities for dialogue between them and the teacher. However, there were predominant educational actions to encourage children to play a role in the games, in choices made and with participation in the routine and in the activities, favoring the construction or strengthening of the autonomy of the children. The social interactions in the games, in school context and that occur between teacher and children and between them are essential for learning and human development, because the school is also a place to live life and childhood.

\section{KEYWORDS}

Social Interactions. Play. Educational Practices. Children. Autonomy.

\section{RESUMEN}

Presenta resultados de una investigación concluida y aborda relaciones sociales entre profesora y niños en contextos de juegos, realizadas en el primer año de la Enseñanza Fundamental. Jugar es acto y aprendizaje social, pero poco presente y valorado en la enseñanza fundamental. El objetivo de describir acciones de interacción docente realizadas con niños en contextos de juegos en la enseñanza fundamental, analizando esas acciones en el proceso de construcción o fortalecimiento de la autonomía de los niños. Fundada en el enfoque cualitativo de investigación, fue realizada por medio de observación participante de la rutina de una clase de niños y su profesora, en contextos de juegos, con registros escritos en diarios de campo. Se trata de veinticinco niños del primer año de la Enseñanza Fundamental y su profesora, de una escuela municipal del interior del estado de São Paulo. Los datos fueron analizados en la perspectiva cualitativa, a partir de la literatura escogida. Se reveló que, en algunas situaciones, los niños podrían haber sido más incentivados y cuestionados, fomentando más oportunidades para el diálogo entre ellas y con la profesora. Sin embargo, predominaron acciones docentes de incentivo al protagonismo infantil en las bromas, en elecciones realizadas y 
con participación en la rutina y en las actividades, favoreciendo la construcción o fortalecimiento de la autonomía de los niños. Las interacciones sociales en los juegos, en contexto escolar y que ocurren entre profesora y niños y entre ellas son esenciales para el aprendizaje y desarrollo humano, pues la escuela es también un lugar para vivir la vida y las infancias.

\section{PALABRAS CLAVE}

Interacciones Sociales; Juegos. Prácticas Educativas; Niños; Autonomía;

\section{INTRODUCÇÃO}

0 presente texto resulta de uma pesquisa concluída e apresenta parte dos resultados encontrados. A investigação foi realizada em contextos de brincadeiras, acompanhando um grupo de crianças do primeiro ano do Ensino Fundamental e sua respectiva professora.

A ludicidade, como um eixo das culturas infantis, equivale a uma significativa atividade interativa própria do ser humano e não apenas de crianças. "Porém, as crianças brincam, contínua e abnegadamente. Contrariamente aos adultos, entre brincar e fazer coisas sérias não há distinção, sendo o brincar muito do que as crianças fazem de mais sério" (SARMENTO, 2003, p. 15). Brincar como ato e aprendizagem social contribui para a resignificação do mundo e expressão da fantasia. No Ensino Fundamental, a partir do primeiro ano, as brincadeiras das crianças dão lugar (ou têm o seu lugar tomado) pelas atividades escolares que visam o trabalho direto com os conteúdos das diversas disciplinas.

No contexto educacional, a brincadeira envolve o processo de ensino, de aprendizagem na realidade infantil e em seu interesse, ao unir o real ao imaginário. Ao brincar, as crianças potencializam-se como sujeitos falantes, que expressam suas representações sobre o mundo. Dessa forma, a brincadeira possibilita que o/a professor/a conheça seu pensamento, interesses e valores das crianças (SOMMERHALDER; ALVES, 2011). Para os autores, nas relações que ocorrem nas brincadeiras, o/a professor/a deve incentivar a construção da autonomia nas diversas práticas que se desenvolvem.

Kishimoto (2010) destaca que o/a professor/a nos momentos de observação, intervenção ou participação nas brincadeiras desempenha um importante papel. A autora ressalta que a estranheza de muitos adultos frente ao brincar com as crianças revela uma concepção escolarizada, voltada às atividades dirigidas pelos adultos e não ao mundo simbólico.

Nas relações com as crianças, o/a professor/a se coloca como parceiro fundamental em seus processos de desenvolvimento. Interagir com as crianças nas escolas significa estimulá-las a construírem novas significações e a relacionarem o que estão aprendendo na escola com experiências vivenciadas fora dela; observar as crianças, apoiá-las, questioná-las, responder às suas perguntas, acalmá-las, motivá-las, ajudá-las a construir seus conhecimentos e suas identidades.

Isso engloba compartilhar com elas aprendizagens, sentimentos, formas de conhecer o mundo e a si; significa rever constantemente sua atuação profissional a partir das informações fornecidas pelas crian- 
ças que, nas relações crianças-adulto (OLIVEIRA, 2007). "Promover a capacidade da criança para relacionar-se desde cedo com parceiros diversos, particularmente com outras crianças” (OLIVEIRA, 2007, p. 209).

As Diretrizes Curriculares Nacionais para o Ensino Fundamental de 9 anos (Resolução CNE/CBE 07/2010) afirmam que envolvendo os princípios éticos das ações pedagógicas estão a autonomia, liberdade, solidariedade, justiça e respeito à dignidade. De acordo o documento Ensino Fundamental de nove anos: orientações gerais (BRASIL, 2004, p. 11), “É [...] imprescindível debater com a sociedade [...] Uma escola que seja um espaço e um tempo de aprendizados de socialização, de vivências culturais [...]”.

Destaca o diálogo e as relações como eixos do trabalho pedagógico ao brincar, rir, acolher, consolar, estabelecer limites, estimular a curiosidade e a autonomia. Ainda conforme esse documento, as experiências das crianças e a qualidade de suas relações com seus pares e adultos determinam as possibilidades de aprendizagem no meio sociocultural, como a família e a escola. A ampliação do Ensino Fundamental para nove anos expande a possibilidade de aprendizagem e de relações, afirma o documento.

Entretanto, se brincar ainda se faz presente na educação infantil, autores como Sommerhalder e Alves (2011), Emerique (2003) evidenciam que na escolarização dos anos iniciais do ensino fundamental, brincar é apagado ou pouco presente enquanto elemento integrador do processo de ensino e de aprendizagem da criança, mostrando-se distante do cotidiano das práticas pedagógicas e quando encontrado, apresenta-se somente em momentos de recreio ou intervalo escolar.

Sobre autonomia, etimologicamente, autós significa por si mesmo e nomos significa lei. Portanto, autonomia significa poder de dar a si a própria lei. Porém, não equivale ao sinônimo de autossuficiência, pois esse poder não é absoluto, depende também do outro (ZATTI, 2007). Ao se perceber e perceber o outro como diferente, a criança começa a acionar seus próprios recursos, o que contribuí para o desenvolvimento de sua autonomia.

Para Bassedas et al (1999) os adultos e as crianças mais velhas ou experientes contribuem para o processo de desenvolvimento da autonomia das crianças. Ao atuar com professores, familiares e seus pares, as crianças são capazes de realizar o que não fariam, caso desacompanhadas. Posteriormente, as crianças conseguirão realizar tais atividades sem o auxílio de um humano mais experiente.

Freire (2003) afirma que a autonomia se constitui na medida em que o sujeito toma decisões de acordo com suas próprias concepções, ideias e valores. A autonomia é conquistada gradativamente, é um processo. Freire aponta a decisão, a responsabilidade e a liberdade como caminhos percorridos para se alcançar a autonomia.

0 presente texto objetiva descrever ações de interação docente realizadas com crianças em contextos de brincadeiras no ensino fundamental, analisando possíveis contribuições dessas ações no processo de construção ou fortalecimento da autonomia de crianças.

\section{CAMINHO METODOLÓGICO}

A investigação realizada buscou fundamento metodológico na abordagem qualitativa de pesquisa. Nesta abordagem, a fonte dos dados é o ambiente natural e coletam-se as informações por meio do contato direto com os sujeitos da pesquisa (BOGDAN; BIKLEN, 1994). 
Ancorado em Cruz (2008, p. 80) considera-se fundamental na pesquisa de campo a "distância e proximidade; familiaridade e estranhamento". Entende-se que na pesquisa com crianças faz-se necessário ouvir o que foi e não foi dito, atentar-se para os silêncios, ao ver e ouvir. Cabe levar em conta que as crianças ainda têm poucas oportunidades de se colocarem como sujeitos, de serem ouvidas. Torna-se necessário, na pesquisa com crianças, exercitar-se em olhar do ponto de vista delas, bloquear um modo de ver anteriormente projetado pelo pesquisador, um olhar de adulto.

Ao suspender o olhar adulto do pesquisador, torna-se possível entender o mundo a partir do ponto de vista das próprias crianças (CRUZ, 2008). Escutar as crianças desmonta o domínio adulto e permite o conhecimento sobre elas. "A experiência da criança como um outro é a atenção à presença enigmática da infância” (LARROSA, 2013, p. 186).

Foram sujeitos, 25 crianças, com seis anos de idade em média, de uma turma do primeiro ano do Ensino Fundamental e sua professora, de uma escola municipal do interior do estado de São Paulo. A instituição localizava-se em um bairro periférico e em uma mesma quadra havia uma instituição de educação infantil, separadas por um muro e que compartilhavam alguns espaços em comum.

A coleta de dados foi realizada por meio de observação participante e com registros escritos em diários de campo, para cada inserção realizada. As inserções em campo de pesquisa ocorreram durante três meses seguidos, em três dias da semana, no período da tarde (13h00 às 17h00) em diferentes espaços da escola, utilizados para momentos de convívio das crianças. Os dados foram analisados na perspectiva qualitativa, à luz do referencial teórico.

Conforme sugerem Bogdan e Biklen (1994) buscou-se analisar os dados com toda a sua riqueza, ao respeitar a forma como os sujeitos manifestaram-se e para tanto, realizou-se registros em diários de campo, descrevendo os acontecimentos e as falas de crianças e professoras. As notas de campo buscaram manter os relatos e pontos de vista dos sujeitos, trazendo as descrições das observações e dos contextos das brincadeiras. A pesquisa foi aprovada no Comitê de Ética em Pesquisa com Seres Humanos, da Universidade. Assim, foram seguidos todos os preceitos éticos de pesquisa científica com uso de nomes fictícios. Neste processo, as próprias crianças escolheram seus nomes fictícios.

\section{RESULTADOS E DISCUSSÃO}

A sessão apresenta os principais resultados encontrados na turma de crianças do primeiro ano do Ensino Fundamental, além de trazer a análise e discussão.

Em uma cena lúdica, a criança Édison solicitou e contou com a ajuda da professora, ao ser empurrado por Jeniffer. A docente interrogou a criança para buscar compreender o que havia ocorrido e com isso ter outros elementos desse contexto da situação. Em seguida, buscou desencadear, por meio da conversa direta com as crianças, uma reflexão sobre as condutas infantis. Para Freire (1997) a relação entre as crianças e a docente exige liberdade e autoridade, estabelecida na base do diálogo. Para ele, o diálogo deve ser democrático, ético e justo para que o educando vivencie e aprenda o que é dito.

Édison disputa um brinquedo com Jeniffer. Édison tenta pegar das mãos de Jennifer uma máscara. A menina o empurra. 
Édison: Professora, a Jeniffer me empurrou.

Professora: Por quê?

Édison: Porque eu queria a máscara que tá com ela.

Professora: Jeniffer, você fez alguma coisa com o Édison?

Jeniffer: Eu só relei.

Professora Isa: Ah, só relou? O Édison falou que você empurrou ele.

Jeniffer: É que ele queria a minha máscara.

Professora: E por isso tem que empurrar?

Jeniffer: Não. (Diário de Campo número 10, turma do primeiro ano do Ensino Fundamental).

Em outra cena, três crianças ficaram sem brincar na brinquedoteca. Nesta situação, a percepção que temos sobre as ações da professora nas relações sociais com as crianças indicam que o brincar foi empregado como controle da produção e do comportamento infantil, em sala de aula. Conforme Sarmento (2003) nas relações humanas que ocorrem em contextos escolares, as crianças aprendem as formas de ser e estar nesse espaço coletivo.

Nesta cena, a ação docente pouco incentivou as crianças a buscarem autonomia na resolução de seus conflitos, na manifestação e negociação de interesses e pode ter colaborado com a compreensão, por parte das crianças, de que as atividades de registro, o silenciamento da voz e do corpo são mecanismos necessários para o acesso ao brincar. Sommerhalder e Alves (2011) destacam que o/a professor/a precisa fomentar a construção da autonomia das crianças em conflitos surgidos ao longo do brincar, para fortalecerem seus posicionamentos e autoestima.

Cabe dizer que no acompanhamento do cotidiano profissional desta docente, percebeu-se que ela recebia fortes cobranças das gestoras escolares e das famílias das crianças sobre as conquistas da alfabetização. Por outro lado, inexistiam expectativas familiares e de gestão escolar, referentes às diversas possibilidades de aprendizagens infantis, por meio de brincadeiras.

Compreende-se que o excesso de atividades pedagógicas para serem realizadas pode ter fragilizado o acompanhamento e o incentivo de interações infantis durante os momentos de brincar das crianças. Sobre esse aspecto, o documento Ensino Fundamental de Nove Anos: orientações gerais (BRASIL, 2004) afirma que o trabalho pedagógico no primeiro ano no Ensino Fundamental deve seguir as premissas apontadas nas Diretrizes Curriculares Nacionais para a Educação Infantil (CNE/ CEB 05/2009), tendo como eixos norteadores o brincar e as interações.

A professora coloca quatro crianças sentadas ao seu lado, pois não tiveram o comportamento desejado em sala de aula e não poderiam brincar. A docente corrigia uma grande pilha de cadernos das crianças. Alessandra vai contar à professora um conflito surgido com outra criança, no momento de brincadeira.

Professora: Ah, se for ficar vindo reclamar, vão ficar sem ir na brinquedoteca.

Um dos meninos que ficou sem brincar começa a chorar. Outro tenta sair do lugar para brincar.

Professora: Se sair do lugar fica sem brincar hoje e na semana que vem.

0 menino volta a se sentar. 
Professora: A Lara pode ir brincar. [Lara permaneceu sentada e quieta ao longo deste tempo. Com a autorização da docente, correu sorridente para brincar]. (Diário de Campo número 13, turma do primeiro ano do Ensino Fundamental).

Em outro dia de observação, as crianças Valter, Leandro e Antônio decidiram brincar de pular corda juntos. Valter solicitou o apoio da professora e da pesquisadora para a brincadeira acontecer. A professora observou, comentou e incentivou Antônio a pular mais rápido, de acordo com a regra da brincadeira, inventada pelas próprias crianças.

A conduta realizada pela professora em acompanhar e incentivar as crianças, nessa brincadeira infantil, valorizou a produção e incentivou a autonomia. O/a professor/a precisa falar e agir com ética e boniteza. O/a educador/a deve querer bem as crianças, agir com alegria, esperança, afetividade, seriedade científica e luta política (FREIRE, 1997).

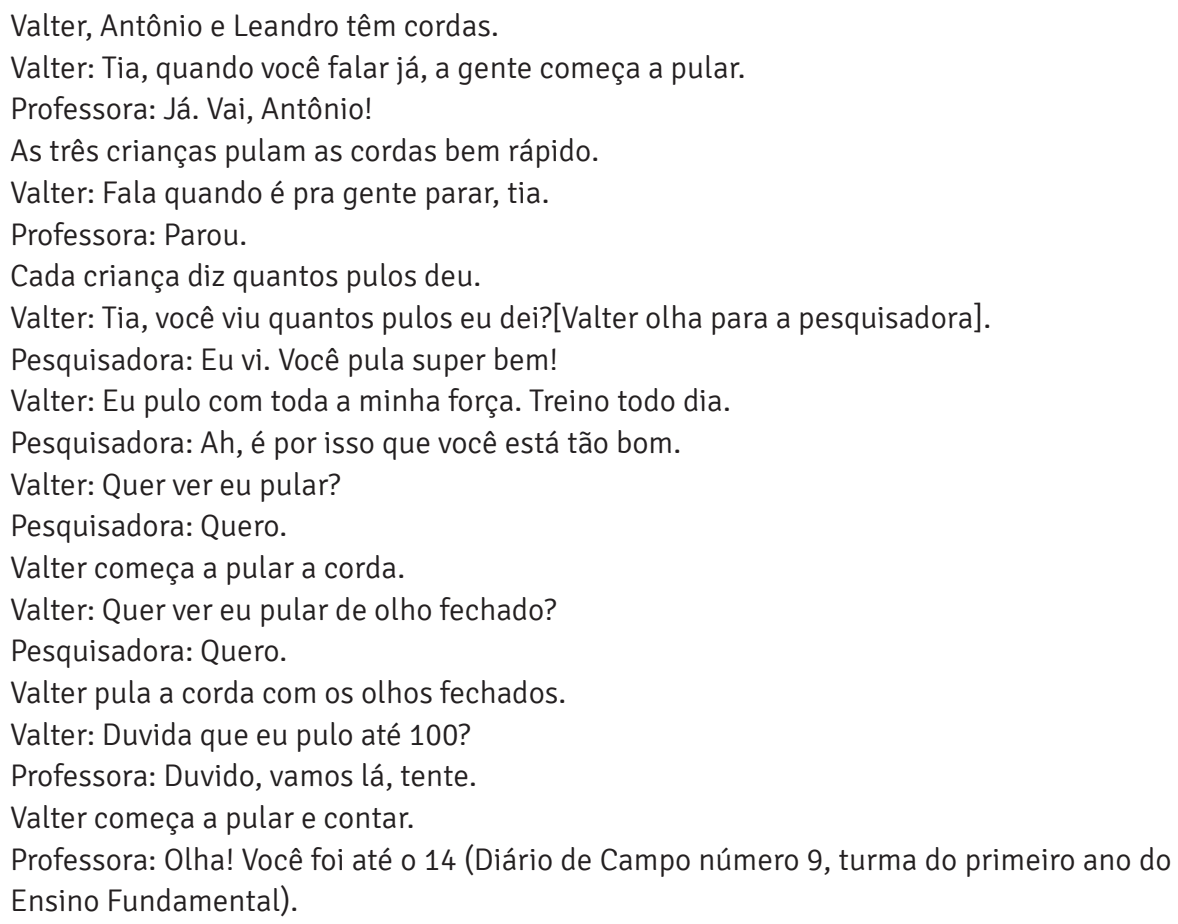

Em outra cena lúdica, a professora decidiu brincar com as crianças de “Nunca Dez”. A docente sugeriu a brincadeira e as crianças manifestaram interesse. Então, diante do aceite ela organizou o brincar. No entanto, as crianças não participaram desta organização como também da criação ou negociação de regras da brincadeira. Duas crianças que saíram da brincadeira acabaram por inventar uma outra e com isso, experienciaram, com outra amplitude, o exercício de governar com maior autonomia seu próprio brincar. 
Professora: As meninas podem vir para frente.

As garotas dirigem-se à frente da sala.

Professora: Agora os meninos.

Os garotos também vão à frente.

Alan: É o recreio.

Professora: Não, não falei pra formar a fila. Querem brincar de "Nunca 10"?

Crianças: Eba!

A brincadeira com suas regras foi explicada pela professora: Organizam uma roda e dizem os numerais de 0 a 9 na sequência da roda. 0 número 10 não poderia ser dito. Quando a criança não acerta o n., todas falam "choca, choca". A criança imita uma galinha ao centro da roda.

Professora: Agora quem errar não vai "chocar", vai sair.

Com a saída de cada participante, o restante comemora. 0 jogo prossegue até chegarem aos três finalistas. Enquanto a brincadeira dirigida ocorre, Alan e Mário se interessam por outra brincadeira.

Alan: Quer brincar, Mário?

Alan mostra um carrinho a Mário.

Mário: Quero.

Alan deita-se de bruços no chão.

Alan: Agora você fica aí.

Mário também se deita um pouco distante de Alan. Um joga o carrinho ao outro. (Diário de Campo número 9, turma do primeiro ano do Ensino Fundamental).

Na cena lúdica que segue, a criança Rodrigo que estava no canto da casinha da brinquedoteca, convidou a professora para a brincadeira de fazer "comidinhas". A brincadeira, invenção da própria criança, foi acolhida pela docente e contou com a sua participação. Conforme o documento Ensino Fundamental de nove anos: orientações gerais (BRASIL, 2004), o diálogo e as relações sociais são o eixo do trabalho pedagógico. Esse documento aponta que, por meio dos eixos norteadores, as crianças e professores brincam, riem, acolhem, consolam, estabelecem limites, estimulam a curiosidade e autonomia. Nesse caso, por meio das relações e do diálogo, Rodrigo e a professora interagiram e brincaram juntos.

Rodrigo: Você gosta de macarrão com molho?

Professora: Eu adoro.

Rodrigo: Então, come. Eu fiz pra você.

Professora: Hum, que delícia!

Rodrigo: Também fiz café.

Rodrigo dá uma xícara de brinquedo à professora.

Professora: Que gostoso!

Rodrigo: Tá forte?

Professora: Não, tá muito bom (Diário de Campo número 9, turma do primeiro ano do Ensino Fundamental). 
A professora, ao encontro do proposto por Bassedas et al (1999) manifestou interesse pela ação lúdica proposta por Rodrigo, acolhendo-a. As trilhas do gradual percurso da construção da autonomia não são lineares, mas sim gradativas. Transcorrem por diferentes momentos, ao incluir dificuldades que podem ser superadas com relações afetivas e de confiança.

Em um outro dia de observação, Rodrigo sugeriu uma brincadeira que foi aceita por todas as crianças da turma e pela professora.

\author{
Rodrigo: Vamos brincar de "Choquinho"? \\ Professora e crianças: Vamos! \\ Sentam-se em círculo de mãos dadas: é a docente quem inicia o disparo dos "choques" e \\ Alan, sentado no polo oposto da roda, indica qual chegou primeiro. 0 "choquinho" consis- \\ te-se em um leve aperto de mão, passado de integrante a integrante. Ao dizer qual time \\ que ganha cada rodada, a equipe comemora. \\ Professora: É hora do recreio, pessoal (Diário de Campo número 7, turma do primeiro ano \\ do Ensino Fundamental).
}

Nessa cena, a professora interagiu com as crianças durante a brincadeira e possibilitou que elas experimentassem a autoria, ampliando a construção da autonomia. Freire (2003) entende o educando como sujeito ao invés de objeto do conhecimento e, nesse processo, maior poderá ser sua criticidade, suas construções perante o aprendido, seus atos e sobre o mundo. Percebe-se, neste exemplo, o respeito ético da professora perante a autonomia da criança na invenção e proposição da brincadeira, ao respeitar sua preferência e interesses de todas.

$\mathrm{O}$ avanço no processo de construção da autonomia de Rodrigo permitiu que ele escolhesse a brincadeira e convidasse todos para brincar com ele. A criança teve confiança e tomou a decisão para realizar a sugestão da ação lúdica. Aos adultos cabe interferir com diferentes graus de ajuda para permitirem gradualmente maior autonomia das crianças (BASSEDAS et al., 1999).

Crianças pequenas adoram jogos e brincadeiras e conseguem extraí-los de qualquer coisa.
[...] o espírito dessas brincadeiras devia ser de alegria, de ingenuidade, de vitalidade, como
é o que move todo bom jogo, toda atividade lúdica, inclusive a brincadeira de tentar desco-
brir como o mundo funciona que chamamos educação [...] Elas dão à criança um sentimento
mais forte de causa e efeito, de uma coisa conduzindo à outra. Também ajudam a criança
a sentir que ela faz a diferença, que é capaz de produzir efeitos no mundo ao redor. Quanta
emoção deve sentir uma criança ao brincar com um adulto, ao sentir que, fazendo deter-
minada coisa, ela pode levar aquele gigante onipotente a também fazer algo, e que pode
manter o jogo em movimento durante o tempo que desejar (HOLT, 2007, p. 49-50).

A participação adulta nas brincadeiras infantis de forma satisfatória, incentivando autonomia, manifestação de interesses, tomada de decisões, recombinação ou criação de regras é qualitativa para o progresso infantil. Moyles (2006) afirma que o/a professor/a que valoriza o brincar pode, por meio de relações e da intervenção, promover aprendizagens e progressos no desenvolvimento infantil, englobando ao currículo a socialização e a construção de mundo pela criança. 
Apesar de compreende-se que a professora, durante todo o período de observação da pesquisa relacionou-se pouco com as crianças nos diversos contextos de brincadeiras, algumas das ações docentes foram incentivadoras para as conquistas de autonomia.

Torna-se fundamental a maior participação dos/as docentes no brincar infantil, pois além de organizarem os objetos e espaços, podem propor desafios, dúvidas, outras brincadeiras ou modos de brincar e assim, trazer novos conhecimentos para as crianças, valorizando e ampliando ainda a cultura lúdica. O/a professor/a pode, em pequenos grupos, motivar a fantasia e simbolismo infantil. Esta intervenção em modo de ajuda pedagógica aumenta a frequência e complexidade da brincadeira, ainda mais se as crianças forem menores e ainda estiverem interessadas pelos jogos de faz de conta.

A intervenção pedagógica pode ser realizada por meio do incentivo com observação e participação. A participação consiste em brincar diretamente com as crianças, enquanto por iniciação compreende-se criar uma situação de brincadeira e sugerir às crianças o brincar. O/a professor/a deve participar e realizar intervenções pedagógicas durante as brincadeiras, contudo sem invadir, decidir ou dominar as crianças com suas falas, gestos e normas. É fundamental nesse processo de conquista ampliada da autonomia, a liberdade também para escolher do que, como e com quem brincar, para tentar e experimentar o acertar ou o fracassar (MOYLES, 2006; SOMMERHALDER e ALVES, 2011).

\section{CONSIDERAÇÕES FINAIS}

As relações sociais entre crianças e professora nas brincadeiras contribuíram para a construção da autonomia das crianças, no que diz respeito à divisão do protagonismo da organização da rotina escolar, da autoria em algumas ações lúdicas, como a escolha de brincadeiras, de brinquedos e parceiros para brincar.

Como a construção da autonomia é um processo, em alguns momentos as crianças encontraram dificuldade no desenrolar das interações ou surgiram conflitos que não conseguiram resolver sozinhas. Nestes momentos, solicitaram auxílio e apoio da professora. Em algumas situações, os resultados mostraram que a professora, de forma prática, rápida e eficiente acabou por decidir, fragilizando o protagonismo infantil ao propor a forma de resolução do conflito, pouco fomentando experiências de diálogo, construção e expressão de argumentos pelas próprias crianças.

Por outro lado, a professora também possibilitou e incentivou a liberdade para as crianças organizarem-se, escolherem, dialogarem, movimentarem-se, relacionarem-se, brincarem, vivenciarem experiências, compartilharem saberes, interesses e valores. Ela compartilhou com as crianças a organização do tempo e do espaço na escola. Considera-se que a autonomia das crianças também depende da liberdade consentida e/ou incentivada pela docente.

Destacamos que as famílias e a gestão escolar, por vezes, atribuem grande valor e cobrança às atividades escolarizantes, os registros e as produções infantis. Esta importância não é atribuída no mesmo teor de relevância às relações sociais ou intervenções pedagógicas que ocorrem nas brincadeiras e as aprendizagens e experiências de autonomia possibilitadas por essas vivências. 
A construção ou o fortalecimento da autonomia nestas crianças está em contínuo processo, também alimentado pelas relações entre elas durante as brincadeiras e em outros momentos vividos no contexto escolar.

Os resultados mostraram que as crianças poderiam ter sido mais incentivadas e questionadas, fomentando mais oportunidades para escolhas, decisões, participação ou mesmo diálogo entre elas e com a professora. Entretanto, considera-se que predominaram ações docentes colaborativas para a construção ou fortalecimento da autonomia destas crianças.

Reforçamos que as ações de interação docente nas brincadeiras são essenciais para as aprendizagens e desenvolvimento humano da criança, assim como as interações entre as próprias crianças, pois a escola é também um lugar para aprender a viver a vida e a infância. As aprendizagens geradas nas relações sociais, por meio das trocas, das experiências, nas mediações do plural de culturas, valores e de conhecimentos desencadeados nas brincadeiras alimentaram a continuidade do progresso de construção da autonomia destas crianças.

\section{REFERÊNCIAS}

BASSEDAS et al. Aprender e Ensinar Na Educação Infantil. Porto Alegre: Artmed, 1999.

BOGDAN, R.; BIKLEN, S. Investigação qualitativa em educação: uma introdução à teoria e aos métodos. Porto: Porto Editora, 1994.

BRASIL. Ministério da Educação e do Desporto. Ensino Fundamental de nove anos: orientações gerais. Brasília, 2004. 27p.

BRASIL. Ministério da Educação. Conselho Nacional de Educação. Resolução CEB n. 5, de 17 de dezembro de 2009. Institui as Diretrizes Curriculares Nacionais para a Educação Infantil. Diário Oficial [da] República Federativa do Brasil, Brasília, DF, 18 dez. 2009. Seção 1, p. 18.

BRASIL. Ministério da Educação. Conselho Nacional de Educação. Resolução CEB n. 7, de 14 de dezembro de 2010. Institui as Diretrizes Curriculares Nacionais para o Ensino Fundamental de 9 (nove) anos. Diário Oficial [da] República Federativa do Brasil, Brasília, DF, 15 dez. 2010. Seção 1, p. 34.

CRUZ, S. H. V. A criança fala: a escuta de crianças em pesquisas. São Paulo: Cortez, 2008.

EMERIQUE, P. Brincaprende: dicas lúdicas para pais e professores. Campinas: Papirus, 2003.

FREIRE, P. Pedagogia da autonomia: saberes necessários à prática educativa. Petrópolis: Paz e Terra, 2003. 
FREIRE, P. Professora sim, tia não: cartas a quem ousa ensinar. São Paulo: Olho d'água, 1997.

HOLT, J. Como as crianças aprendem. Campinas: Verus Editora, 2007.

KISHIMOTO, T. M. (Org.). 0 brincar e suas teorias. São Paulo: Cengage Learning, 2010.

LARROSA, J. O enigma da Infância: ou o que vai do impossível ao verdadeiro. In:

LARROSA, J. Pedagogia profana: danças piruetas e mascaradas. Belo Horizonte: Autêntica Editora, 2013. p. 183-198.

MOYLES, J. R. A excelência do brincar. A importância da brincadeira na transição entre educação infantil e anos finais. Porto Alegre: Artmed, 2006.

OLIVEIRA, Z. M. Educação infantil: fundamentos e métodos. São Paulo: Cortez, 2007.

SARMENTO, M. J. As culturas da infância nas encruzilhadas da $\mathbf{2}^{\mathbf{a}}$ modernidade. Braga: Instituto de Estudos da Criança, Universidade do Minho, 2003.

SOMMERHALDER, A.; ALVES, F. D. Jogo e a educação da infância: muito prazer em aprender. Curitiba: CRV, 2011.

ZATTI, V. Autonomia e educação em Immanuel Kant e Paulo Freire. Porto Alegre: Edipucrs, 2007. 
1 Mestre em Educação pela UFSCar; Pedagoga; Professora de Educação Infantil; Membro do Grupo de Estudos sobre Processos Educativos de Crianças/CNPq. E-mail: camilatanureduarte@gmail.com

2 Doutor em Educação Escolar; Licenciado em Educação Física; Professor do Programa de Pós-Graduação em Educação e do Dep. de Educação Física e Motricidade Humana Universidade Federal de São Carlos - UFSCar, Departamento de Educação Física e Motricidade Humana/ CCBS; Membro do Grupo de Estudos sobre Processos Educativos de Crianças/CNPq; Coordenador do Centro de Pesquisa da Criança e de Formação de Educadores da Infância-CFEI. E-mail: fdalves@ufscar.br

3 Doutora em Educação Escolar; Pedagoga; Professora do Programa de Pós-Graduação em Educação e do Dep. de Teorias e Práticas Pedagógicas, Universidade Federal de São Carlos -UFSCar, Departamento de Teorias e Práticas Pedagógicas - $\mathrm{CECH}$; Coordenadora do Grupo de Estudos sobre Processos Educativos de Crianças/ CNPq; Coordenadora do Centro de Pesquisa da Criança e de Formação de Educadores da Infância - CFEI. E-mail: sommeraline1@gmail.com

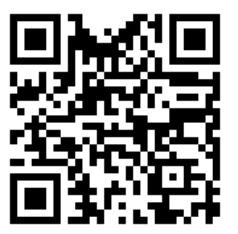

A autenticidade desse artigo pode ser conferida no site https://periodicos. set.edu.br

\section{(2) (1) (-)}

Este artigo é licenciado na modalidade acesso abertosob a Atribuição-Compartilhalgual CC BY-SA

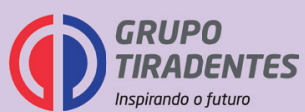

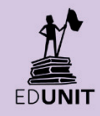


